\title{
Festa de Inauguração do Centro de Turismo e Lazer: uma análise da performance identitária dos Laklãnõ (Xokleng) de Santa Catarina
}

\author{
Esther Jean Langdon \\ Pesquisadora CNPq / Universidade Federal de Santa Catarina, Florianópolis, Brasil \\ estherjeanbr@yahoo.com.br
}

\section{Flávio Braune Wiik}

Universidade Estadual de Londrina, Londrina, Brasil

flaviowiik@gmail.com 


\section{Resumo}

O presente artigo analisa a Festa de Inauguração do Centro de Turismo e Lazer dos Laklãnõ, realizada em 2003, na Terra Indígena Ibirama, Santa Catarina. A festa tinha como objetivos lançar publicamente a cooperativa de artesanato indígena, ampliar o mercado dos artesanatos, assim como promover a identidade do grupo, tanto para os jovens indígenas, quanto para o público não-indígena. A estes, soma-se o de apresentar a "cultura" através de discursos sobre o passado "no mato", cânticos no idioma, ritos antigos, arquitetura e comida tradicionais e de jogos indígenas. A partir das discussões antropológicas contemporâneas sobre cultura, estética e autenticidade das performances indígenas, a festa será analisada à luz dos processos de construção de identidade indígena em dialogo com os discursos locais, nacionais e internacionais, nos quais o índio autentico figura positivamente. A festa trata da revitalização identitária do grupo e de sua história diante do discurso nacional e global de multiculturalidade, onde os Laklãnõ apresentam-se concomitantemente como "índios crentes" e "índios puros".
Abstract

This article analyzes the Festival of Inauguration of the Tourism and Leisure Center of the Laklãno Indians, held in 2003 on the Ibirama Indian Reserve, Santa Catarina, Brazil. The Festival had as its objectives the publicizing of the Cooperative, the amplification of the cooperative's market, and also the promotion of the group's identity for the Indian youth as well as for a non-Indigenous public. They presented "culture" through discourse about the past "in the forest", songs in the native language, ancient rituals, Indian games and traditional food and architecture. Using contemporary anthropological discussions on culture, esthetics and the performance of Native authenticity, the Festival is analyzed in the light of the processes of the construction of indigenous identity in dialogue with local, national and international discourse, in which the authentic Indian figures positively. The festival involves the revitalization of the group's identity and its history before the national and global discourse of multiculturalism, where the Laklãno affirm themselves to be simultaneously evangelical as well as pure Indians.

Keywords: Performance, Xokleng, Identity Politics

Palavras-chave: Performance, Xokleng, Políticas Identitárias 


\section{Introdução}

Recentemente, Oakdale chamou atenção para o fato de que a perforRmance da cultura de forma consciente é um fenômeno recorrente em todo o mundo, e se faz presente através de eventos interétnicos e interculturais tais como: festivais nacionais, encontros indígenas regionais, protestos transnacionais, fóruns globais e exibições (2004: 60). De fato, o número de publicações antropológicas sobre este tema tem aumentado consideravelmente, inclusive no Brasil. Temos constatado a existência de muitos trabalhos dedicados a questão da performance cultural entre grupos indígenas na Amazônia e nordeste (e.g.: Conklin 1997; Conklin and Graham 1995: Graham 2005; Turner 1991; Grunewald 2005). Entretanto, como bem aponta Oakdale (2004), poucos estudos têm analisado eventos locais voltados, preferencialmente, para os públicos locais. Mais ainda, pouca atenção tem sido dada às performances culturais dos grupos indígenas no sul do Brasil. Este fato, em parte, deve-se às características não exóticas e pouco atraentes destes índios que vivem as margens da sociedade envolvente. Em comparação com a região amazônica, estes grupos têm sido ignorados pelas organizações não-governamentais nacionais e internacionais dedicadas às questões ambientais e de etno-desenvolvimento (Conklin e Graham 1995). Do mesmo modo, apenas recentemente estes grupos começaram a formar as suas próprias organizações, criadas com o objetivo de entrar em diálogo com as instâncias governamentais e com programas e projetos a eles dirigidos pela sociedade civil.

A partir deste contexto, o presente artigo tem como objetivo contribuir com os estudos sobre performances culturais ao descrever e analisar um evento local entre os índios Laklãnõ (Xokleng) de San- 
ta Catarina: "Festa de Inauguração do Centro de Turismo e Lazer", organizada pela Cooperativa Indígena Aldeia Figueira (COOIAF). À luz de recentes pesquisas sobre representação de identidades em performances culturais, analisaremos como esta festa torna evidente a relação existente entre a revitalização da identidade Laklãnõ e as políticas culturais brasileiras avançadas pelas agências nacionais indigenistas, o contexto histórico regional e a conversão dos Xokleng ao pentecostalismo.

Ambos os autores têm realizado pesquisas de campo entre os Xokleng (Langdon e Rojas 1991; Wiik 2004; Langdon et. alli. 2006). A primeira conhece o grupo desde 1985, e o segundo realiza pesquisas intensivas desde 1996. Estas experiências de longa data respaldam a análise da festa que foi observada pela primeira autora para fins didáticos atrelados à disciplina "Simbolismo: do rito para performance" oferecida na Universidade Federal de Santa Catarina, em 2003. Além das pesquisas dos autores, o Programa de Pós-graduação em Antropologia Social da UFSC tem uma longa trajetória de pesquisas e colaboração com o grupo, lideradas, principalmente, pelo professor Sílvio Coelho dos Santos. Ele iniciou seu trabalho entre os Xokleng na década de 1960 e, ao longo de sua carreira como professor da UFSC, inspirou, orientou e treinou inúmeros alunos e pesquisadores. Sua produção bibliográfica sobre o grupo é vasta, sendo Os Índios Xokleng: Memória Visual, publicado em 1997, um marco da recuperação de documentos e fotos produzidos sobre os Xokleng ao longo de quase um século. Devido aos seus esforços, a UFSC tem sido considerada um centro de pesquisa sobre relações interétnicas, impactos de projetos de desenvolvimento, educação e outros tópicos que tratam dos índios de Santa Catarina, particularmente dos Xokleng.

\section{Os Xokleng}

Os índios Xokleng, cuja maioria passou a autodenominar-se Laklãnõ, há poucos anos atrás, são os remanescentes de grupos seminômades do tronco linguístico Jê, que ocupavam as encostas das montanhas, os vales litorâneos e das bordas do planalto sul do Brasil. Segundo Santos (1997; 16) e Urban (1996: 43), o nome Xokleng é apenas uma identificação dos brancos, principalmente dos antropólo- 
gos, e que os índios em si não possuíam termo de autodenominação específico, apesar de que se diferenciavam dos Kaingang e Guarani grupos vizinhos com os quais disputavam território desde o processo expansionista da sociedade nacional. Regionalmente, ficaram conhecidos como Botocudos e, mais pejorativamente, como os Bugres. ${ }^{1}$

Somam hoje cerca de um mil e quinhentos indivíduos agrupados na Terra Indígena Ibirama (TII), que também tem sido, nos últimos anos, designada pelos índios como Terra Indígena Laklãnõ, local em que foram reunidos pelo Serviço de Proteção ao Índio (SPI) a partir de 1914. A TII está situada na região do alto vale do rio Itajaí, a cerca de $260 \mathrm{~km}$ ao noroeste de Florianópolis, capital de Santa Catarina. Ela ocupa uma área de 14.156 hectares, situada predominantemente entre os municípios de José Boiteux e Vitor Meireles. A menor unidade social de cooperação e de produção predominante é a de família extensa, ou dos grupos domésticos. Outrora coletores e caçadores, os Xokleng hoje sobrevivem da agricultura de subsistência e do extrativismo, de atividades produtivas como diaristas sazonais na região, prestadores de serviços aos colonos locais, aos comerciantes de madeira, como funcionários dos órgãos públicos, tais como FUNAI e Funasa, além das pensões dos idosos, projetos assistenciais do Estado e da filantropia. O artesanato ainda representa um aporte mínimo de renda para as famílias. ${ }^{2}$

\section{Contexto histórico da festa}

A história de contato dos Xokleng com a sociedade envolvente tem sido predominantemente marcada por longos e profundos conflitos das mais diversas ordens. Ela tem início em meados do século XVIII, com a expansão das fronteiras nacionais rumo ao planalto serrano dos estados do sul do Brasil - terras até então de ocupação tradicional dos Kaingang e Xokleng - a cabo de tropeiros, bandeirantes, madeireiras, companhias ferroviárias e de colonização. À esta, soma-se o povoamento sistemático do médio e alto vale do rio Itajaí-Açu a partir de meados do século XIX por imigrantes europeus, assentados na região através das companhias de colonização, o que afetou diretamente os Xokleng que ocupavam a região. Com a sua chegada, iniciamse décadas de conflitos e mortes de indígenas e colonos na região (Santos 1978; Penny 2003). Como resposta, e em face do projeto de 
colonização estar ameaçado pela presença indígena na região, grupos paramilitares financiados pelo governo, com apoio das companhias de colonização, denominados "bugreiros", adentravam as matas para "caçar" os Xokleng. Estimava-se que sua população no início do século totalizava entre 400 e 600 indivíduos, divididos em três subgrupos, ou "facções": os Laklãnõ, que habitavam a região do Alto Vale do Itajaí, os Ngrokòthi-tõ-prèy, do Planalto Serrano, e os Angying, da Serra do Tabuleiro. ${ }^{3}$ Em 1914, os remanescentes Xokleng, sobreviventes à estas ações, foram finalmente aglutinados em uma área reservada que compreende aproximadamente à área da TII na atualidade - sob a tutela do SPI comandado por seu chefe local, Eduardo de Lima e Silva Hoerhann, em um épico até hoje representado nas festas e datas comemorativas locais.

Superada a fase crítica das relações belicosas travadas entre os Xokleng, colonos e demais moradores do local, a depopulação dos Xokleng aglutinados na TII ficou a cargo das epidemias que os levaram ao quase extermínio. Entre 1914 e 1932, epidemias de gripe, sarampo e tifo reduziram a população em dois terços, ou seja, de 400 para 150 indivíduos (Henry 1941; Urban, 1985). O impacto provocado pelas epidemias também trouxe rupturas socioculturais (Ribeiro, 1982, 1991; Santos, 1973; Urban, 1985). As mortes em massa fizeram com que os sobreviventes se dispersassem pela floresta, interrompendo a execução do ritual anual de iniciação dos jovens e o de cremação dos mortos, ambos centrais para a reprodução de sua sociedade.

Hoerhann, aclamado pelos não-indígenas como "pacificador", foi o primeiro chefe do posto indígena, função que exerceu por mais de quatro décadas, tendo seu papel pautado em extremo rigor. A rispidez militarista fundante do próprio SPI, o exemplo familiar de seu tio materno, Luís Alves de Lima e Silva, o Duque de Caxias e o germanismo, somados ao ethos dos colonos locais, parecem ter inspirado Hoerhann em sua empreitada civilizadora imposta aos Xokleng. Esta tinha como objetivos centrais transformá-los em agricultores, e restringir a sua circulação às áreas a eles destinadas.

Em alguns períodos, Hoerhann mostrou-se bastante criativo em seu projeto, ao cunhar uma moeda local de circulação restrita à TII objetivando instruir os Xokleng noções de valor e troca frente à produção 
agrícola e o modelo econômico dominante. Além de manter um número expressivo de funcionários do SPI em atividades agrícolas e de manutenção do Posto visando "ensinar" estes ofícios aos Xokleng, ele desloca, de outros estados do Sul, Kaingang já acostumados com a lida da terra para estimular os Xokleng à desempenhar mesma tarefa. Mais tarde, abriga expressivo grupo de Cafuzos provenientes da região da guerra do Contestado para trabalharem na agricultura (Martins 1995).

Porém, o projeto civilizatório mostrou-se árduo, sendo marcado por uma série de conflitos e contradições. Parece que a maior parte dos Xokleng resistiu a todos estes esforços, deixando-os trabalhar para eles, enquanto mantinham atividades comuns ao seu histórico seminomadismo. Sua resistência era, e de certa forma ainda é, vista pelos não indígenas como sinônimo de "preguiça", "insolência" e "insubordinação", constatação esta suficiente para Hoerhann tomar ações menos criativas ou "civilizadas" em sua empreitada. O uso da força física e da violência contra os índios era alternativa comum, sendo que escoltas armadas e a cavalo saiam à procura de índios desobedientes e desertores. Prisões, acusações e processos criminais por homicídios de indígenas pesaram sobre Hoerhann, até seu afastamento definitivo da chefia do posto.

Após das primeiras décadas do período pós-contato, caracterizadas pelas mortes em massa causadas pelas epidemias, os Xokleng começam a enfrentar periódicas ações predatórias resultantes das frentes de exploração e subtração dos recursos naturais existentes na TII. Como resultado, os Xokleng têm, por quase um século, sido afetados por períodos de sistemática extração de palmito, implantação de serrarias na TII para retirada e beneficiamento de madeiras nobres, invasão dos limites demarcados por comerciantes, colonos e madeireiras da região. Estas ações têm se dado ao longo do tempo e, na maioria das vezes, com a anuência e/ou "vista grossa" do SPI/FUNAI, assim como através da manipulação de algumas lideranças indígenas por pessoas atreladas a estas frentes e interesses. Tais ações têm se tornado fonte de grandes conflitos, tanto internos quanto externos aos limites da Terra Indígena, sendo também responsáveis pela depredação ambiental, onde o relevo montanhoso de clima subtropical não é mais coberto pela mata atlântica original. A estas, soma-se o fato de que a

\section{ILHA}


entrada abrupta de capital nas fases de extrativismo predatório têm gerado profundas rupturas no tecido social xokleng, pois trata-se de uma sociedade cujos valores, hierarquias, relações sociais e práticas de reciprocidade não são alicerçados na propriedade privada, acumulação de moeda e bens e/ou em um modelo econômico mercadológico (ver Werner 1985; Wiik 2004).

Um exemplo recente e emblemático acerca do impacto causado por estas ações iniciou-se em meados dos anos setenta, época em que cerca de dez por cento da área mais plana e produtiva da TII, onde habitavam os índios, começou a ser inundada em função da construção da Barragem Norte, a qual represou o rio Hercílio - antigo Itajaí do Norte - que corta a TII. Apesar de algumas ações indenizatórias previstas terem sido cumpridas, os impactos trazidos pela sua construção têm sido profundos para os Xokleng até os dias atuais, trazendo rupturas sociais, culturais, econômicas, políticas, médicas e ambientais (Santos 1991; Werner et. alli. 1987). Como exemplo, tem sido constatado o aumento do faccionalismo interno e a fragmentação da única aldeia central em várias aldeias muito dispersas (Werner 1991; Muller 1988). Já nos anos 80, surgiu o primeiro caso de HIV/AIDS entre os Xokleng, um fato altamente divulgado por ter sido o primeiro caso oficial da enfermidade detectado entre índios no Brasil (Langdon e Rojas 1991; Wiik 2001).

Estas ações predatórias devem ser compreendidas como sendo o denominador comum que tem caracterizado a história de contato dos Xokleng com a sociedade nacional, onde estas se dão em razão da expansão das fronteiras nacionais, do incremento da exploração de recursos naturais locais, das políticas integracionistas e desenvolvimentistas iniciados em meados do Século XIX. Ao final, observa-se o confronto de modelos societários adversos, providos de poderes assimétricos.

Os Xokleng têm respondido de forma enérgica a estas ações. Desde os anos 50 do século passado eles têm se organizado de forma a impor e compor a sua agenda frente às mesmas. Mobilizaram-se junto ao poder político local para destituir Hoerhann nos anos 50, e têm participado, mesmo que minimamente, das vantagens econômicas dos ciclos de exploração dos recursos naturais de sua Terra. Eles têm contestado energicamente as deliberações julgadas desvantajosas pela liderança política indígena encaminhamentos feitos por parte da administração local da 
FUNAI, inclusive destituindo administradores e chefes do posto (como aconteceu às vésperas da Festa de Inauguração do Centro de Turismo e Lazer, em julho de 2006, quando tomaram como reféns três funcionários do DSEI Sul/Sudeste da Fundação Nacional de Saúde (FUNASA) em Santa Catarina, em manifestação de sua insatisfação com os serviços de saúde prestados (Assis 2006: 21). Principalmente a partir dos anos 80, os Xokleng têm se mobilizado para receber integralmente as indenizações e benfeitorias acordadas como compensação pela construção da barragem, invadindo seu canteiro de obras, construções e maquinaria. Ademais, a sua luta pela ampliação dos limites da TII vem ganhando corpo junto ao governo federal nos últimos anos.

Em resumo, a postura dos Xokleng frente às instâncias e representantes dos programas governamentais voltados para as sociedades indígenas se dá como nas primeiras décadas do contato, isto é, marcada por uma constante tensão e intensas negociações.

Importante mediador da resistência social e reestruturação política xokleng, observada a partir dos anos 50, tem sido a apropriação do cristianismo pentecostal pelos índios, e tornada forma de expressão e identidade cultural dominantes. Desde esta década, componentes de sua cultura e das formas de organização social têm sido justapostos e reformulados à luz do cristianismo - que foi introduzido entre eles por missionários da Igreja Pentecostal Assembleia de Deus - e, mais recentemente, pelas mãos de uma liderança religiosa autóctone. A versão do pentecostalismo xokleng tem servido de base para a reorganização e reunificação da sociedade. A grande maioria dos Xokleng se declara "crente". Ser "crente" não se restringe a abstrações teológicas individuais a respeito da fé; "crer" e ser "crente" revelam-se através do cumprimento de princípios e dogmas "crentes" que dão diretrizes e valor às práticas coletivas cotidianas. Converter-se em "crente" é fenômeno coletivo, é congregar em uma comunidade de "irmãos". Ser "crente" é também categoria identitária e diferenciadora que o grupo estabelece em relação a outras sociedades, mas, paradoxal e concomitantemente ampliadora de suas alianças com outros grupos indígenas e não-indígenas, também considerados "irmãos", responsável pela formação simbólica uma nação pan-indígena de articulação sociopolítica frente aos desafios impostos pela sociedade envolvente 
(Wiik 2004). Desta forma, o pentecostalismo xokleng tem sido um importante articulador e mediador da cultura, dinâmica social e política desta sociedade até o presente.

A partir da Constituição Federal de 1988, tem-se observado uma mudança importante a respeito da posição dos índios na sociedade brasileira. A política que identificou a presença dos índios como um atraso para o progresso da nação, e que procurava integrá-los à sociedade e economia nacionais, foi substituída pelo reconhecimento do caráter pluriétnico e multicultural da nação. A Constituição dedicou um capítulo aos indígenas, assegurando-os "direitos originários sobre as terras que tradicionalmente ocupam", além de reconhecer sua organização social, costumes, línguas, crenças e tradições próprios. Como consequência, as políticas nas áreas de educação, saúde e ambientais têm se preocupado com a preservação e recuperação de aspectos tradicionais das culturas indígenas. Criou-se no Brasil um contexto favorável à manifestação da identidade indígena, e, além do crescimento das políticas públicas voltadas para fornecer formas de atenção culturalmente sensíveis, o movimento tem sido fortalecido através da formação acelerada de novas associações indígenas, particularmente, pela criação de grupos locais organizados. Vários grupos indígenas "emergentes" também surgiram nos últimos anos do anonimato, não porque fossem isolados, "descobertos" ou contatados recentemente, mas porque o contexto atual favorece à manifestação de sua identidade.

Como já havíamos observado (Wiik 2004), os Laklãnõ, evangélicos pentecostais desde meados dos anos 50, justapõem sua identidade religiosa de "índio crente" à outra categoria êmica, parte de sua identidade étnica, a de "índio puro". Ou seja, os Laklãnõ, ao interagirem com os missionários pentecostais, iniciaram um processo político e sociocultural de identificação do "outro". Porém, este "outro", ao mesmo tempo em que começa a fazer parte de sua percepção acerca da diferença, também tornou-se parte constitutiva dos discursos identitários particularizadores dos integrantes desta sociedade. Trata-se de um exemplo clássico de como a alteridade desencadeia processos dialéticos de rupturas e continuidades; ou mesmo, como tem argumentado Sahlins, de como os modelos "nativos" acabam por traduzir e filtrar elementos exógenos, transformando-os, ou pelo menos fazendo-se passar 
por endógenos e/ou autóctones. Este processo nos remete à dialética da deliberada intenção de pasteurização protagonizada pela globalização e as inesperadas e imprevisíveis respostas locais desencadeadoras de processos de "reetnização" e "etnogênesis" de grupos ameríndios. ${ }^{4}$

Ao final, e em resposta ao novo contexto nacional valorizador da autenticidade e da "pureza" indígena, como argumentado acima, os Laklãnõ, de forma bem particular, justapõem a autenticidade étnica através do conceito de "índio puro" a traços pentecostais através do conceito "Xokleng crente", igualmente "puro", caso sigamos a lógica nativa.

Na TII, evidências das novas políticas públicas visando ser culturalmente sensíveis se manifestam através da presença de atividades promotoras da "cultura tradicional" nas mais diversas áreas a cargo de ONGs, agências governamentais como a Funasa, Funai e Secretaria de Educação, via agentes indígenas de saúde, e programa de educação bilíngue, dentre outras. Os Xokleng, que sempre têm expressado a sua resistência à integração nacional, têm respondido positivamente a estas novas políticas culturais. Sendo assim, processos de retradicionalização, de "mostrar a cultura xokleng", do "índio puro" estão em franca ascensão, evidenciados através da organização da própria Festa de Inauguração do Centro de Turismo e Lazer, da casa da cultura, do galpão de danças, da educação bilíngue, dentre outros. Como a análise a seguir evidenciará, as atividades e práticas que ressaltam a identidade xokleng são destaques dos resultados alcançados pelas políticas públicas e crescimento da importância do índio na legislação e no imaginário brasileiros sobre direto a cultura e práticas tradicionais, assim como instrumento fundamental utilizado pelos índios ao reivindicarem a ampliação de seu território tradicional junto à Funai e demais instâncias públicas e da sociedade civil.

\section{A festa}

Durante o segundo semestre de 2003, um pequeno cartaz em papel tamanho A4 fotocopiado circulou pelos prédios da UFSC anunciando a Festa de Inauguração do Centro de Turismo e Lazer, a ser realizada na aldeia Figueira, na Terra Indígena Ibirama, no dia 3 de dezembro. Sua organização estava a cargo da Cooperativa Indígena Aldeia Figueira (COOIAF), e o cartaz listava como apoio a Fundação

\section{ILHA}


Universidade Regional de Blumenau (FURB), a União e Solidariedade das Cooperativas Empreendimentos de Economia Social (UNISOL), uma deputada, e o programa Arte na Sala da Aula. Dentre as atividades previstas, destacavam-se a inauguração do Centro de Turismo e Lazer e a Trilha Ecológica até a cachoeira da Volta Fria; a exposição de uma oca indígena típica dos ancestrais do povo xoklengue ( sic); apresentação do coral "Lírios do Vale"; danças e comidas indígenas; exposição e venda de artesanatos; jogos indígenas, entre estes, a corrida do toro, o torneio de tiro ao alvo com "arco e flecha" e "sarabatana", cabo-deguerra e a maratona de 100 metros para adultos e crianças.

Além do nosso desejo em prestigiá-la e reforçarmos nossos laços com os Xokleng 5 , ponderamos que a nossa participação na festa representaria uma boa oportunidade para que os alunos da disciplina conhecessem uma performance indígena, e decidimos realizar uma viagem como atividade extra-classe. Entramos em contato com o professor Sílvio com o intuito de saber mais detalhes sobre a festa. Na ocasião, expressou que havia problemas de organização. Afirmou que a COOIAF tinha pretensões de envolver a participação de todas as sete aldeias da Terra Indígena na organização, porém, havia surgido alguns conflitos entre seus organizadores e as lideranças, associados a problemas de comunicação, todos comuns à própria organização política dos Laklãnõ, formada por aldeias providas de autonomia política e marcadas, muitas vezes, por faccionalismos internos ${ }^{6}$. Depois, descobrimos que os problemas de comunicação também diziam respeito à data do evento no cartaz que chegou até a UFSC. Com uma certa dificuldade, descobrimos que a festa seria realizada no dia 13 de dezembro, e não no dia 3, como anunciado. Tal alteração fez com que somente um pequeno grupo de alunos pode realizar a viagem até a TII. Como o semestre letivo já havia sido encerrado e a turma de alunos já dispersara, ao invés de um ônibus da Universidade, seguimos viagem pela manhã, no dia 13, em dois carros, levando oito pessoas interessadas em participar da festa, inclusive um cinegrafista encarregado de filmá-la.

Era um dia chuvoso e a viagem atrasou. A aldeia Figueira situa-se a aproximadamente dez quilômetros do limite norte da Terra Indígena Ibirama e a vinte quilômetros da cidadezinha mais próxima, José 
Boiteux. A TII é cortada por estradas de chão, dificilmente transitáveis em dias chuvosos com automóveis sem tração nas quatro rodas. Ao descermos dos carros, ouvimos o Hino Nacional tocar, e, ao nos direcionarmos ao local do evento, nos deparamos com o vice-presidente da COOIAF, que se apresentou, nos saudou, e, em seguida, afirmou ser o responsável pelo convite feito à UFSC, através do professor Sílvio Coelho dos Santos, no mês anterior. Solicitamos e obtivemos a sua permissão para filmar, e subimos um pequeno aclive rumo ao evento.

O espaço selecionado para a abertura da festa era localizado em um lugar limpo e plano, na base de um morro atrás da casa do cacique da aldeia, onde ainda restava parte da mata atlântica que, no inicio do século 20, ainda predominava no litoral e vales do interior do Sul do Brasil, onde a maior parte da área da TII se localiza. Nesta área, havia um plano um pouco mais elevado que servia de "palco" para as primeiras apresentações e atividades. À direita estava uma enorme caixa de som, ao seu lado esquerdo ficava o coral "Lírios do Vale", um grupo predominantemente composto de mulheres Laklãnõ vestidas com blusas laranja e saias azulescuro. Atrás do palco, uma trilha subia o morro, onde também havia algumas barracas com artesanato expostos para a venda.

Encerrada a execução do Hino Nacional, o presidente da COOIAF deu as boas vindas aos presentes, desejando que a festa se perpetuasse e congregasse o maior número de pessoas nas próximas edições. De lá, tornou pública nossa presença, anunciando ao microfone a chegada do "pessoal de Florianópolis", talvez com o intuito de animar a plateia, inferior à esperada. A plateia se espalhava em frente ao palco, e somava aproximadamente 60 pessoas, entre índios e não-índios, estes últimos sendo da região. Ficou óbvio que o número de espectadores foi considerado baixo pelos organizadores, fato que permeou todos os discursos de abertura da festa. E, ao pensarmos que esta festa foi orientada para turistas e, subsequentemente, para a venda de artesanato, a quantidade de objetos postos a venda superou exageradamente o potencial de compra dos visitantes presentes.

Iraci Paté, professora bilíngue, iniciou a abertura da festa expressando seu orgulho em apresentar "a festa que a gente faz". Em seguida, apresentou o prefeito de Vitor Meireles, que tomou o microfone e agradeceu a oportunidade de falar. Afirmou que a festa iria demonstrar 
a simplicidade e humildade dos "nossos que gostam de fazer festa no meio do mato para demonstrar como viviam antigamente". Sua fala foi seguida pela do cacique Antônio Caxias Popó, da aldeia Figueira, e pela do cacique da aldeia Coqueiros.

Antonio Caxias Popó, além de cacique da aldeia que sediava a festa, é pastor do templo da Igreja Assembleia de Deus instalado junto aos domicílios que compõem o grupo doméstico por ele liderado. Popó saudou os participantes em nome de Jesus Cristo, e anunciou que a festa iria demonstrar para os visitantes e para as crianças indígenas que não conheceram os índios "do mato" como eles viviam nos tempos passados.

Depois destas breves falas introdutórias de boas vindas e agradecimentos, a professora Paloma, da FURB, foi chamada à frente do palco, sendo apresentada como uma mulher muito bem quista pela comunidade, tendo desempenhado importante papel na organização da festa. Ao proferir suas primeiras palavras, se emocionou e chorou, afirmando que não conseguir falar mais. Em seguida, tomou a palavra um não-indígena associado à cooperativa, proclamando a COOIAF como sendo a primeira cooperativa indígena no Brasil. Também relatou sobre as dificuldades enfrentadas durante a organização da festa, afirmando que a sua realização representaria um futuro melhor para os índios. Em seguida, descreveu a programação da festa, estimulando as pessoas a comprarem os artesanatos que estariam à venda, sendo os recursos gerados revertidos à comunidade indígena.

Sua fala foi seguida pela apresentação do coral "Lírios do Vale" conduzido pelo pastor-cacique Popó, que entoou o hino evangélico intitulado "O Jordão não passarei só" traduzido para o xokleng. Depois, entoaram o mesmo hino em português. Antes, o pastor, emocionado, ressaltou a importância da língua nativa para a construção da identidade indígena.

Em seguida vieram os discursos. O primeiro e mais longo foi proferido por um pastor não-indígena, convidado pelo pastor-cacique Popó. Sua fala ocorreu seguindo o estilo de oratória própria à dos pastores evangélicos em suas pregações aos fiéis. Falando em voz alta, plena de repetições, apelou para que a prefeitura (de Vitor Meireles), órgãos oficiais e pessoas públicas prestassem maior ajuda para a co- 
munidade xokleng. Exalta que a festa não estava acontecendo por acaso, mas por obra divina. Também apresentou o grupo historicamente, invocando a imagem dos índios nos tempos antes do contato quando, segundo ele, "viviam em um estado puro com a natureza nas suas malocas". Eles, afirmou,

eram um povo da natureza e desfrutaram dos recursos naturais ... Lutavam incansavelmente para a sobrevivência. Hoje estão com saudades da verdade, do tempo do mato, quando não tinham conhecimento de dinheiro, do preço do feijão e das outras coisas da civilização. Eles eram inocentes, tinham liberdade, liberdade que foi perdida com o contato [com os brancos] e a introdução dos pecados da civilização.

Enquanto proferia sua pregação exaltando, com nostalgia, o passado e lamentando as mudanças advindas com o contato, vários índios começaram a se emocionar, e algumas mulheres do coral choraram. Em seu discurso-pregação, o pastor estimulou os participantes da festa a comprarem o artesanato, qualificando-os como "fruto da natureza divina". Ao final, concluiu com a ideia de que com a salvação de Jesus Cristo, os Xokleng retornaram ao estado de pureza com liberdade.

Cabe ressaltar novamente que sua fala foi ganhando gradativamente forma de pregação, comum ao universo religioso pentecostal, tendo muitas frases terminadas com "aleluias", e estes respondidos coletivamente pelos Xokleng. Seu discurso-pregação foi encerrado com um outro hino evangélico cantado pelo coral, em português.

Em seguida, um jovem professor xokleng fez uma homenagem aos "primeiros pacificadores" que, segundo ele, os ajudaram se tornar "índios civilizados". "Graças a Deus que eles fizerem isto, ou não teria esta festa hoje", afirmou. Com uma lista nas mãos, leu os seus nomes: Wayãkü, Womblê, Waipõ e Lino Nunc-Nunforo, sendo este último citado como "o primeiro professor indígena". Ao apresentá-los, se emocionou e chorou ao afirmar que eles lutaram "para que hoje os índios tenham professores, tenham líderes caciques". "Foram homens guerreiros e lutadores", prosseguiu. No final de sua fala, afirmou que Josué Caxias Popó, antiga liderança, também lutou pelos direitos indígenas.

Finda a homenagem póstuma, o jovem apresenta "o homem mais velho do grupo", um homem "do tempo do mato" que sabe cantar como os antigos". Este senhor apresentou-se vestindo um blazer e um

\section{ILHA}


chapéu de palha industrializado. Antes de cantar, assegurou: "Sou índio de verdade e me lembro do tempo do mato". Então inicia seu cântico ritual, auxiliado pelo som de um chocalho que balança ao cantar. Sua apresentação encerra a abertura da festa.

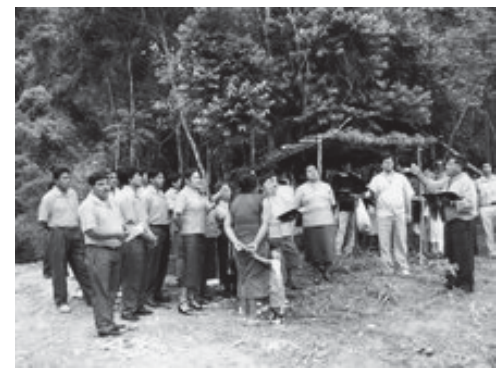

Homem do tempo do mato descansando.
Apresentação do coral "Lírios do Vale".

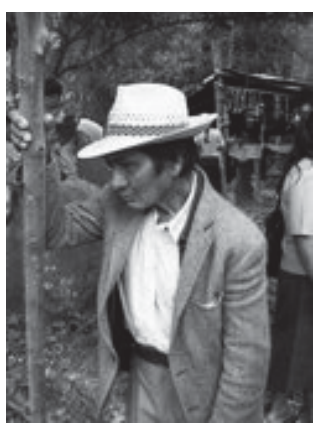

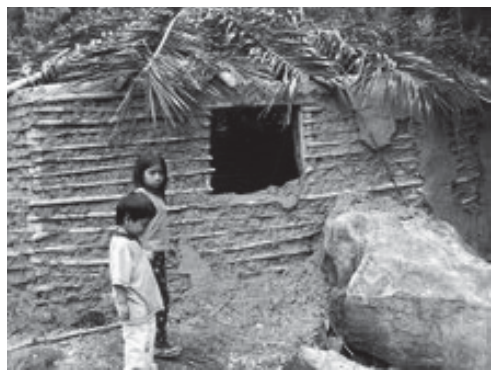

Venda de artesanato.

Em seguida, fomos convidados a subir a trilha pela mata até a "oca tradicional", onde estavam programadas danças, venda de artesanato, comidas tradicionais e jogos. No caminho, passávamos ao longo das barracas que expunham o artesanato, objetos que consistiam em muitos colares e brincos de sementes e em algumas machadinhas e bastões xokleng, maracás enfeitados com penas coloridas, miniaturas 
de arco e flecha e de sarabatanas de bambu. Ao longo da trilha, outras mulheres xokleng circulavam entre os participantes da festa oferecendo colares de sementes, e crianças pediam esmolas aos não-indígenas.

Ao final da trilha, nos deparamos com um espaço limpo, como uma clareira, mais ou menos plana no meio da mata. Várias pedras haviam sido pintadas com motivos indígenas, tais como arco e flecha e a lança típica xokleng. As pinturas nas pedras também indicavam os caminhos para a oca indígena, para os banheiros e para a trilha da cachoeira, que, ao final, não foi terminada. A oca consistia em uma construção arredondada feita de pau-a-pique com aberturas de janelas e uma porta. $\mathrm{O}$ telhado, de folhas de palmeiras, não havia sido terminado. A clareira também contava com barracas para a venda de artesanatos e alguns locais destinados aos fogos de chão para assar peixe do rio e carne. $\mathrm{O}$ peixe assado, representando a comida indígena, vinha acompanhado por "totolo", milho moído e cozido dentro de talos de bambu.

Ao chegarmos à clareira, iniciaram a dança. Um grupo de índios entrou na clareira dançando em círculos, cantando e balançando maracás. O grupo era formado por dois homens mais velhos, cinco mulheres e um menino de mais ou menos oito anos de idade. Este menino era o único entre os jovens e adultos masculinos a trajar estojo peniano conforme fotografias pós-contato datadas do início do Século XX (ver Santos 1997). Os corpos das mulheres estavam cobertos por fibras de palmeira. Os homens adultos vestiam calções e estavam sem camisa. Seus rostos estavam pintados com círculos (cheios e vazios) ou linhas retas, lembrando as representações gráfico-corporais das metades kaingang observadas na realização da festa de Kiki, entre os Kaingang de Xapecó, nos anos 90 (Tomasino e Rezende, 2000).

Finda a dança, o jovem professor anunciou que o grupo iria apresentar o rito de batismo tal qual era realizado "no tempo do mato". Uma mulher com uma criança no colo sentou-se junto ao chão, no centro de um grupo disposto em círculo. Estes dançaram e cantaram ao seu redor. O rito foi seguido pela "dança da viúva" com uma mulher idosa sentada ao centro. ${ }^{7}$ Enquanto o grupo dançava, um homem idoso se aproximou dançando ao lado da mulher sentada no chão para dar conselhos. Em seguida, mais uma mulher adentrou o círculo dançando até parar e findar o movimento.

\section{ILHA}


Fomos convidados para entrar na "oca tradicional" e cumprimentar a mulher mais idosa do grupo, identificada como uma "índia pura do mato", Ayu Paté ${ }^{8}$, com 123 anos de idade. O apresentador afirmou que "ela nasceu no tempo do mato e, por ser índia pura, ainda está forte, boa da vista e do ouvido". Ela não falava português, e estava acompanhada por um intérprete. Cada um de nós foi convidado a cumprimentá-la e oferecer uma "colaboração". Algumas pessoas entraram na oca, cumprimentaram-na e deixaram notas de cinco ou dez reais, enquanto outros tiravam fotos.

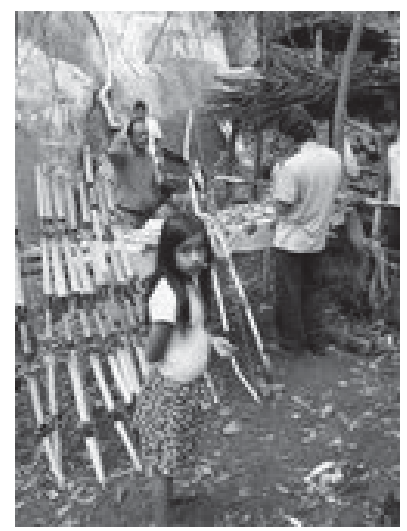

Venda de artesanato.

Depois de uma pausa destinada para pessoas comprarem artesanatos e almoçarem, os jogos iniciaram. A primeira competição foi a de arco e flecha. Os organizadores estimulavam, em especial, aos nãoindígenas a participarem, cada um pagando uma taxa para competir. O grande arco tradicional dos Xokleng, usado para atirar flechas ao alvo, provou ser bastante difícil para quem não estava acostumado a manuseá-lo, o que causava muitos risos por parte dos índios para com os não-índios, quando estes não conseguiam fazer a flecha atingir o alvo, ou cair ao chão antes de ser lançada. Em seguida houve a competição de zarabatanas, miniaturas feitas de bambu. Entre os comentários, um participante anunciou, "sou alemão, tenho que soprar forte". Durante os jogos, observava-se uma constante jocosidade em torno das relações entre índios e colonos locais. Os ganhadores receberem medalhas penduradas em fitas azuis. 
Todas as outras atividades anunciadas no cartaz da festa, exceto a maratona, não aconteceram. A trilha para a cachoeira não foi terminada e as outras competições, tais como a "corrida do toro", não foram sequer mencionadas. Terminada a competição com zarabatanas, as pessoas foram convidadas para participar da maratona, que seria realizada na estrada. Competir neste evento também exigia o pagamento de uma pequena taxa, mas poucos demonstraram interesse em participar. Muitos já se preparavam para retornar para as suas casas.

Ao descermos a trilha em direção a estrada para assistirmos à maratona, começou uma leve chuva, e a festa encerrou rapidamente. Enquanto os poucos homens ainda corriam a maratona, os índios empacotavam e organizavam rapidamente seus pertences e partiam. O mesmo se deu com os não-indígenas que vieram participar da festa. Vários índios subiram na boleia de uma caminhonete da Funasa, que partiu entre os últimos dois homens que chegavam ao término da maratona. As medalhas foram entregues aos finalistas, mas não havia plateia para conferir o êxito alcançado. Todos estavam com pressa de sair. E assim a festa terminou abruptamente.

\section{Análise}

Esta festa, como expressão da identidade étnica frente aos próprios Xokleng e população regional demonstra características diferentes dos eventos observados no passado (e até mesmo no presente: tipo ocupação da barragem) que tratavam de situações de colaboração ou confronto com a sociedade envolvente. Por exemplo, o professor Sílvio observa que os índios Xokleng visivelmente demonstravam vergonha quando convocados a desfilar "vestidos e enfeitados como índio" em frente dos colonos em Ibirama, em 1962 (1978:33;1997: 108). Urban observa que, na década de 1970, os Xokleng tinham abandonado a sua vestimenta e arquitetura tradicionais. Os homens não usavam mais o botoque, característica do grupo que deu origem a sua identificação como "botocudos". Exteriormente (e aos olhos dos "ocidentais"), não apresentavam características de uma cultura indígena. Ainda, o autor observa que, na época, eles pareciam aos olhos ocidentais, quase antiexóticos na suas tentativas de evitar chamar atenção como um grupo culturalmente distinto da sociedade envolvente (Urban 1996:15). Em

\section{ILHA}


1970, a exibição performática da identidade indígena ainda não era usual nem tampouco apreciada era a força imagética do índio tradicional como recurso de resistência política. Não obstante, as expressões de resistência dos Xokleng ao longo de sua história demonstraram que as tentativas de assemelhar materialmente aos colonos não representam um concomitante declínio da identidade indígena, nem consistiam em intuito de apagar a sua identidade grupal.

Também já havíamos observado celebrações que demonstravam pouco interesse para com as tradições do passado. Por exemplo, a celebração do dia do índio, em 1996, na aldeia Bugio, limitou-se a entoar o Hino Nacional, o hasteamento da bandeira e discursos dos políticos locais e lideranças indígenas. Recordamos neste dia de um ancião, que nascera antes da "pacificação", e que ainda tinha a cicatriz no lábio inferior perfurado para inserção do botoque, estar sozinho em um canto de uma casa vizinha ao evento, tocando maracá e cantando canções rituais sem despertar qualquer interesse por parte dos indígenas ou visitantes. Este comportamento vai ao encontro do que os Xokleng nos relatavam nos anos 90, que sentiam vergonha de se apresentar nas cidades, que tinham vergonha de sua "cultura"

Já em 2003, a festa sugere que os Xokleng são conscientes do discurso internacional em que as imagens corporais do índio nu representam o "selvagem nobre ecológico" (Conklin 1997: 713). Ambos Conklin e Turner ( 1991) chamam atenção do fato da representação da cultura autêntica através do corpo tem sido uma estratégia importante, e que a roupa se tornou uma marca da identidade e de resistência. Conklin e Graham ( 1995) apontam para a relação entre o movimento ecológico e o movimento indígena na Amazônia. Apesar de os Xokleng estarem fora desta região e não participarem no diálogo com as ONGs dedicadas à preservação ecológica, a representação de sua cultura demonstra que estão conscientes deste discurso e do poder político do índio autêntico e ecológico. Assim, eles falam sobre seu passado com orgulho e nostalgia, ressaltando a importância de mostrar a sua cultura, tanto para as visitas quanto para os jovens indígenas que não a conheciam. Seu idioma, sua vestimenta antiga, seus rituais e outras características de sua vida tradicional são postos em exibição como traços diacríticos de sua identidade, e, diferente de 1996, os idosos são 
honrados como exemplos do tempo do mato, época antes do contato. Ainda mais, a criação do "espaço do mato" como palco da sua vivência tradicional, com sua arquitetura, comida, ritos, jogos e outras atividades, também os estabelece como autênticos e legítimos para expressar suas demandas frente a sociedade envolvente, o movimento ecológico e as políticas públicas.

A análise da estética da festa demonstra a construção de uma narrativa histórica contada pelos Xokleng, que comunica uma imagem positiva não só da época pré-contato como também dos processos históricos que trouxeram a escola e o pentecostalismo, aspectos estes que lhes permite hoje identificarem-se como Xokleng crentes. A estética do passado se expressa na língua, na seminudez e pintura corporal, no canto do homem ancião e nas danças dos ritos. Esta amalgama-se à estética evangélica, nos hinos do coral e na oratória do pastor, evocando coros e "aleluias" dos Xokleng crentes.

Entrelaçado com a estética, a história contada nos discursos da festa afirma uma identidade positiva e contrastante com os preconceitos que os índios enfrentam na região, acusados de não serem mais índios, de não terem mais cultura e de serem preguiçosos, sujos e bêbados. Temos escutado frequentemente dos colonos vizinhos, queixas que os Xokleng não são como os índios puros da selva amazônica, que, todavia, mantém sua cultura. Os discursos da festa dialogam com esta imagem negativa do índio "civilizado", e apresentam uma outra perspectiva. O pastor não-indígena, em sua longa pregação, a resume. O "tempo do mato" e a inocência natural foram destruídos. O contato trouxe a decadência com a civilização. A subsistência tradicional com base nos frutos da natureza divina foi substituída pela pobreza e pela dependência do dinheiro. Porém, com a conversão, foi reinstaurado o estado divino. O jovem professor, em sua homenagem aos índios pacificadores, aos que lutaram por seus direitos e para sua educação, orgulha-se da festa, afirmando que seus antepassados, através de seus esforços possibilitaram os Xokleng tornarem-se civilizados.

O passado, durante a festa, é reinventado através de uma imitação relativa aos registros fotográficos que captaram a imagens dos Xokleng no início do século XX (Santos 1997). A oca "típica" inacabada feita de pau-a-pique, de fato, representa as que foram introduzidas com a

\section{ILHA}


confinação dos Xokleng na TII e como o fim da vida seminômade, e não seus abrigos temporários no mato. As vestimentas e a seminudez dos índios que realizam os ritos demonstram elementos que sugerem o estilo de se vestir e ornamentar no passado, mas o uso da palha para cobrir partes do corpo é uma inovação cuja finalidade é produzir um estado de seminudez relativo a nudez evidenciada nas fotos. A ação ritual também não representa os ritos completos do passado, mas reproduzem fragmentos de processos rituais mais complexos, como os observados durante a encenação do ritual de alijamento e reagregação das viúvas. Também, o canto do ancião é realizado por ele sozinho, sem o contexto do evento tradicional que trata de um "canto dialógico" com seus ouvintes, geralmente composto por membros mais jovens de seu grupo doméstico.

Os jogos também representavam habilidades do passado, mas não os reproduziram, salvo, talvez, o uso do arco grande na competição dos homens adultos. As zarabatanas utilizadas são brinquedos, tanto quanto os arcos e flechas usados na competição dos meninos. Os dois jogos que não aconteceram, porém anunciados no cartaz, o cabo-de-guerra e a corrida de toro, não têm registros na literatura etnográfica acerca do grupo. Porém, se tornaram símbolos famosos de jogos indígenas via a divulgação dos mesmos no Xingu. Eles fazem parte, também, da recém criada "olimpíadas indígenas", evento de destaque nacional com a participação dos vários povos indígenas do Brasil

Entre os eventos anunciados no cartaz, porém não realizados durante a festa, encontra-se a trilha ecológica até a cachoeira da Volta Fria. Apesar da trilha evidentemente não ter sido finalizada a tempo da festa, a intenção demonstra a consciência dos Xokleng para com a imagem nacional e internacional do índio ecológico, a promoção de turismo sustentável e a comercialização de objetos fabricados a partir da natureza (Conklin 1997; Conklin e Graham 1995). Assim, a representação do mato como o lugar da autenticidade do índio verdadeiro, a ligação da clareira no mato com as atividades de turismo, dos jogos, e a presença constante da venda dos colares, brincos e outros objetos artesanais fabricados a partir dos produtos da natureza ("da natureza divina" como disse o pastor), são parte dos objetivos comerciais da festa. 
Se no passado, os Xokleng tentaram afirmar seus direitos sem chamar a atenção das suas particularidades culturais, torna-se claro que, durante a festa, estão em sintonia dialogal com os discursos da política que circula desde a década de 1980 nos cenários nacional e internacional, e que percebem as vantagens da identidade indígena.

\section{Comentários finais}

Nas ultimas décadas, o tema da performance da cultura tem se tornado um importante tópico da etnologia (Ramos, 1987, 1995; Jackson 1991, 1995; Conklin 1997; Conklin e Graham 1995; Turner 1991). Mais recente, Graham (2005) argumenta que estas performances fazem parte da política identitária ou mesmo das políticas de identidade.

Turner (1991) chama a atenção para o fato do crescimento da consciência do poder da identidade indígena no Brasil já na última década do século vinte. Ramos (1998) também tem discutido os vários aspectos atrelados à identidade indígena no âmbito das políticas públicas, apesar deste segmento representar somente $2 \%$ da população nacional. Conklin, e Graham (1995), dentre outros, têm argumentado que a performance do índio autêntico na atualidade deve ser analisada como resultado da colaboração de organizações não governamentais (ONG), em especial as estrangeiras, para com as sociedades indígenas da Amazônia e do Brasil Central. Preocupações ecológicas e a imagem de que "índios exóticos" são protetores naturais do meio ambiente foram sobrepostas no imaginário ocidental, expressas em forma de um esforço global para responder aos problemas ambientais atuais, assim como para estimular a autosustentabilidade das populações nativas expostas à economia de mercado capitalista. A este movimento "preservacionista" deve-se somar os interesses de grandes capitalistas na era pós-moderna altamente tecnológica, muitíssimo interessados nas fontes de riqueza da Amazônia, não somente em termos de matéria prima para o seu desenvolvimento (madeiras e minérios), que tem sido explorados de forma predatória e sem racionalidade até então, para um interesse sobre a "biodiversidade" e "conhecimentos tradicionais", que, por sua vez, podem garantir enormes lucros quando atrelados às tecnologias "limpas", altamente lucrativas, que se autoreproduzem e/ ou podem ser sintetizadas em laboratórios (como é o caso de matéria

\section{ILHA}


prima para remédios ou projetos genéticos patenteados a posteriori com base nos conhecimentos tradicionais).

Quanto à percepção positiva que a sociedade brasileira, em geral, tem sobre a identidade indígena, esta se deve ao crescimento e fortalecimento do movimento indígena nos últimos trinta anos no Brasil, que, por sua vez, consolidou-se através de um conjunto de leis próprias a estas sociedades a partir da Constituição de 1988; que lhes garantiu o direito de expressarem livremente seus costumes e tradições, assim como organizarem-se sociopoliticamente de forma autônoma, e escolher livremente modelos econômicos que lhes garantam a sobrevivência física em suas terras. ${ }^{9}$

Fora da região amazônica, comunidades indígenas do nordeste brasileiro despontaram-se no cenário nacional nas últimas duas décadas. Comunidades previamente consideradas parte indiferenciada da população denominada "cabocla" ou "tapuia" do nordeste, têm sido reconhecidas como providas de identidades indígenas distintas e próprias, em um movimento denominado "etnogênesis" (cuja contrapartida das próprias sociedades indígenas tornaram-se mister). Diante da falta de um idioma ou outras práticas que os distingam de vizinhos nãoindígenas, o ritual denominado "toré" e sua performance tornaram-se características diacríticas de autoridade e representação de identidade tribal no nordeste (Grunewald 2005; Oliveira 1999; Viegas 2001).

As sociedades indígenas do sul do país também têm se beneficiado e ativamente respondido à crescente importância da identidade indígena, assim como das políticas públicas de inclusão cultural. Programas de saúde e educação voltados para as populações autóctones da região sul têm recebido financiamentos públicos crescentes na última década. Programas promotores das ideologias de identidade étnica e participação indígena na execução dos mesmos têm crescido circunstancialmente. Ademais, observa-se a colaboração de ONGs em programas de promoção de saúde, educação e desenvolvimento econômico nas TIs, apesar destas parcerias darem-se mais em nível nacional com recursos públicos ou através de atividades de pesquisa e extensão de universidades da região.

Algumas razões podem explicar esta característica. São estas: o fato dos índios do sul não estarem incluídos no imaginário ocidental de exotismo como alguns grupos indígenas da Amazônia e do Xingu o 
são, assim como localizarem-se em áreas urbanas, com o meio ambiente muito degradado, e/ou por estarem em regiões cujas riquezas naturais já se encontrarem profundamente dilapidadas, e, finalmente, por terem sido ofuscadas pelo conceito da aculturação, amplamente difundido entre as sociedades brasileira e internacionais como um todo. ${ }^{10}$

Neste contexto e escopo de análise proposto pelo presente artigo, talvez a característica que mais distinga os índios do sul frente aos demais da região amazônica, serrado e nordeste, seja a ausência de organizações indígenas fortes e representativas como observada nestas outras regiões. As populações Jê e Guarani do sul, embora numericamente consideráveis, estão representadas por poucas organizações de natureza local, tendo pouca expressão na arena nacional das políticas indigenistas. Porém, como demonstrado pela festa dos Xokleng, os índios do sul estão manifestando a consciência do valor da imagem do índio autêntico nas políticas de identidade e expressando uma redefiniçãa do poder e visibilidade destas sociedades à luz das ideologias dominantes no cenário indigenista atual, talvez novas reetinizações (Baniwa 2008) estejam a caminho dos índios do sul.

Por fim, apesar de as performances culturais destes grupos estarem atuando como instrumento edificador da crescente identidade étnica entre os mesmos, poucos estudos antropológicos têm se dedicado à análise destas performances de forma comparativa frente ao observado em outras partes do Brasil, ou em outras partes.

Sendo assim, a Festa de Inauguração do Centro de Turismo e Lazer aconteceu em meio a um contexto cujo olhar é favorável ao índio puro, que vive junto à natureza, tido como seu principal guardião, mesmo que esta tenha traços de recriação e incorporação de elementos e materiais exógenos ao seu passado material e imaterial (como a "oca" dentre outros), ou que elas se dêem em um ambiente físico degradado - como é o caso da TII inundada por um lago de contenção provocado pela construção da barragem - sem florestas nativas, devastadas a partir dos anos 80. Ademais, a "autenticidade indígena" apresentada no escopo do cenário nacional, aos olhos dos Laklãnõ, perpassa o campo culturalreligioso, onde os índios puros são os pentecostais, evidenciando, desta forma, que os projetos globais de autenticidade são, em ultima instância, subjacentes ao crivo da autenticidade e da legitimidade locais. 


\section{Notas}

1 Henry (1941) e Mussolini (1980) erroneamente os haviam identificado como Kaingang em suas publicações.

2 Para informações etnográficas mais detalhadas acerca do grupo ver Henry 1941; Santos 1997; Urban 1978, 1996; Wiik 2004.

3 Os Ngrokòthi-tõ-prèy foram contatados na primeira década do seculo 20 e os Angying nunca foram contatados oficialmente, acreditando-se na sua extinção (ver Urban 1978; Santos 1973; Wiik 2004). Sobre o subgrupo do Planalto Serrano ver Pereira 1995).

4 Para maiores detalhes deste processo de reetnização e etnogênese entre os povos indígenas no Brasil ver Gersem Baniwa (2008) e Oliveira Filho (1998). Ver Bartolomé (2006) para uma revisão geral.

5 Além das pesquisas que realizamos no passado, pretendíamos iniciar um novo projeto de pesquisa em Janeiro de 2004.

6 Para mais detalhes sobre organização social e dinâmica política dos Xokleng ver Muller 1988; Santos 1973; Urban 1978; Wiik 2004.

7 Este rito deve representar a reintegração da viúva após ausentarem-se fisicamente de seus respectivos grupos domésticos com a morte dos maridos. Urban (1996: 15) descreve duas cerimônias, segundo o autor, ainda praticadas no período de sua pesquisa nos anos 70, a reclusão da viúva e a festa de reintegração.

8 Uma foto dela está publicada em Santos (1997: 142).

9 Para maiores detalhes vide Gersem Baniwa 2008.

${ }^{10}$ Recentemente, os Kaingang da Terra Indígena Xapecó fundaram um Organização não Governamental para gerir os recursos provenientes do Governo Federal destinados à saúde indígena, fato que pode ser o prenuncio de mais organizações administradas pelos indígenas no sul do Brasil.

\section{Bibliografia}

ASSIS, Evandro de. Índios fazem três reféns em José Boiteux. Diário Catarinense, 12 jul. 2006. p. 21

BANIWA, Gersem. $O$ indio brasileiro: o que você precisa saber sobre os povos indígenas no Brasil de hoje. Brasília: Unesco; MEC, 2008. (Coleção Educação para Todos).

BARTOLOMÉ, Miguel A. As etnogêneses: velhos atores e novos papéis no cenário cultural e político. Mana, v. 12, n. 1, p. 39-68, 2006.

CONKLIN, Beth. Body paint, feathers, and videos: aesthetics and authenticity in Amazonian activism. American Ethnologist, v. 24, n. 4, p. 711-737, 1997.

CONKLIN, Beth; GRAHAM, Laura R. The shifting middle ground: Amazonian Indians and eco-politics. American Anthropologist, v. 97, n. 4, p. 695-710, 1995.

GRAHAM, Laura R. Image and instrumentality in a Xavante politics of existential recognition: the public outreach work of Eténhiritipa Pimentel Barbosa. American Ethnologist, v. 32, n. 4, p. 622-641, 2005.

GRÜNEWALD, Rodrigo de Azeredo (Org. ). Toré: regime encantado do índio do Nordeste. Recife: Fundação Joaquin Nabuco; Massangana, 2005. 
HENRY, Jules. Jungle people: a Kaingang tribe of the highland of Brazil. Richmond, VA: The William Byrd Press, 1941.

JACKSON, Jean. Being and becoming an Indian in the Vaupés. In: URBAN, Greg; SHERZER, Joel (Ed.). Nation States and Indians in Latin America. Austin: University of Texas Press, 1991.

JACKSON, Jean. Culture, genuine and spurious: the politics of indianness in the Vaupês, Colombia. American Ethnologist, v. 22, n. 1, p. 3-27, 1995.

LANGDON, Esther Jean; ROJAS, Blanca Guilhermina. Saúde: um fator ignorado numa situação de mudança rápida: a situação da área indígena Ibirama (SC). In: SANTOS, Sílvio Coelho dos (Org.). A barragem de Ibirama e as populações atingidas na área indígena: documento-denúncia. Boletim de Ciências Sociais, Florianópolis: UFSC, v. 51, 1991. p. 65-89.

LANGDON, Esther Jean et al. A participação dos agentes indígenas de saúde nos serviços de atenção à saúde: a experiência em Santa Catarina (Distrito Sanitário Especial Indígena Interior Sul). Cadernos de Saúde Pública, v. 22, n. 12, p. 2637-2646, 2006.

MARTINS, Pedro. Anjos de cara suja: etnografia da comunidade cafuza. Petrópolis, RJ: Vozes, 1995.

MÜLLER, Sálvio A. Opressão e depredação: a construção da barragem de Ibirama e a desagregação da comunidade indígena local. Blumenau: Ed. da FURB, 1988.

MUSSOLINI, Giocondo. Os meios de defesa contra a moléstia e a morte em duas tribos brasileiras: Kaingang de Duque de Caxias e Bororo Oriental. In: Ensaios de antropologia indígena e caiçara. Rio de Janeiro: Paz e Terra, 1980.

OAKDALE, Suzanne. The culture-conscious Brazilian Indian: representing and reworking indianness in Kayabi political discourse. American Ethnologist, v. 31, n. 1, p. 60-75, 2004.

OLIVEIRA FILHO, João Pacheco de. Uma etnologia dos “índios misturados"?: situação colonial, territorialização e fluxos culturais. Mana, v. 4, n. 1, p. 4777, 1998.

OLIVEIRA FILHO, João Pacheco de. A viagem da volta: etnicidade, política e reelaboração cultural no Nordeste indígena. Rio de Janeiro: Contra Capa, 1999.

PENNY, Glenn. The politics of anthropology in the age of empire: German colonists, Brazilian Indians, and the case of Alberto Vojtech Fric. Comparative Studies in Society and History, v. 2, n. 45, p. 249-280, 2003.

RAMOS, Alcida Rita. Reflecting on the Yanomami: ethnographic images and the pursuit of the exotic. Cultural Anthropology, v. 2, n. 3, p. 284-304, 1987.

RAMOS, Alcida Rita. O índio hiper-real. Revista Brasileira de Ciências Sociais, v. 28, n. 10, p. 5-14, 1995.

RAMOS, Alcida Rita. Indigenism: ethnic politics in Brazil. Madison: University of Wisconsin Press, 1998.

RIBEIRO, Darcy. Os índios e a civilização. Rio de Janeiro: Vozes, 1982.

\section{ILHA}


RIBEIRO, Darcy. A pacificação dos Xokleng. Revista Carta: falas, reflexos, memórias, Brasília: Impressão Gráfica do Senado Federal, n. 9, p. 23-53, 1991.

SANTOS, Sílvio Coelho dos. Índios e brancos no Sul do Brasil: a dramática experiência Xokleng. Florianópolis: Edeme, 1973.

SANTOS, Sílvio Coelho dos. O homem índio sobrevivente do Sul: antropologia visual. Florianópolis; Porto Alegre: Garatuja, 1978.

SANTOS, Sílvio Coelho dos (Org.). A barragem de Ibirama e as populações atingidas na área indígena: documento-denúncia. Boletim de Ciências Sociais, Florianópolis: UFSC, n. 51, 1991.

SANTOS, Sílvio Coelho dos. Os índios Xokleng: memória visual. Florianópolis: Ed. da UFSC; Univali, 1997.

TOMMASINO, Kimiye; REZENDE, Jorgisnei Ferreira de. Kikikoi: ritual dos Kaingang na área indígena Xapecó/SC: registro áudio-fotográfico do ritual dos mortos. Londrina: Midiograf, 2000.

TURNER, Terence. Representing, resisting, rethinking: historical transformations of Kayapo culture and anthropological consciousness. In: STOCKING, George (Ed.). Colonial situations. Madison: University of Wisconsin Press, 1991.

URBAN, Greg. A model of Shokleng social reality. Tese (Doutorado em Antropologia) - Universidade de Chicago, 1978.

URBAN, Greg. Interpretations of inter-cultural contact: the Shokleng and Brazilian national society 1914-1916. Ethnohistory, v. 32, n. 3, p. 224-244, 1985.

URBAN, Greg. Metaphysical community: the interplay of the senses and the intellect. Austin: University of Texas Press, 1996.

VIEGAS, Susana de Matos. Trilhas e identidades entre os índios do Sul da Bahia. In: RAMALHO, Maria; RIBEIRO, A. S. (Org. ). Entre ser e estar: raízes, percursos e discursos da identidade. Porto, Portugal: Afrontamento, 2001. p. 185-212.

WERNER, Dennis W. Mudanças demográficas no Posto Indígena Ibirama. Anais do Museu de Antropologia, Florianópolis, v. 15, n. 16, p. 24-34, 1983.

WERNER, Dennis W. Psycho-social stress and the construction of a flood-control dam in Santa Catarina, Brazil. Human Organization, v. 44, n. 2, p. 161-167, 1985.

WERNER, Dennis W. et al. As enchentes do Vale do Itajaí, as barragens e suas conseqüências sociais. Cadernos de Ciências Sociais, Florianópolis: UFSC, v. 7, n. l, 1987.

WIIK, Flávio Braune. Contato, epidemias e corpo como agentes de transformação: um estudo sobre a AIDS entre os índios Xokléng de Santa Catarina, Brasil. Cadernos de Saúde Pública, v. 17, n. 2, p. 397-406, 2001.

WIIK, Flávio Braune. Christianity converted: an ethnographic analysis of the Xokleng "Laklano" Indians and the transformation resulting from their encounter with Pentecostalism. Tese (Doutorado em Antropologia) University of Chicago, 2004. 